Again, why give the reader so little of Sir John Lubbock, and so much of other authors? De Saussure and Favre may indeed have "made" the geology of Mont Blanc, but why these long French quotations from their writings? Does the Pavillon de Bellevue stand in need of a testimonial to its beauty from any French writer, even Favre? (p. 327). A graver objection to Sir John Lubbock's treatment of the Mont Blanc massif is the inadequate account of its geotectonic relations. It is impossible to satisfactorily explain the "causes to which Mont Blanc is due," without setting forth its relations to the fold "trough" of the Briançonnais and the broken western end of the Valais "crest" of mountains. It is, indeed, the greatest blemish in Sir John Lubbock's book that he nowhere gives a geological insight into the structure of the Monte Rosa massif of mountains from the Simplon Pass to the St. Bernard. Yet this area is the Swiss frontier, whereas the Mont Blanc massif is almost wholly French and Italian. However fully, then, the succeeding chapter on "The Valais" treats the Rhone Valley, it misses its mark with regard to the mountains. The few notes on Zermatt and the Matterhorn, on p. 357, are quite insufficient.

The Bernese Oberland is more deftly handled than Mont Blanc. The intricacies of the overfold of gneiss are explained, and there are no fewer than six geological sections from Fellenberg and Baltzer to illustrate the fourteen pages. The Rhone, Upper Aar, Reuss, Ticino, and Rhine valleys are treated much after the fashion of the Swiss "Livret-Guide" referred to above, although without its daily itinerary. In these chapters we are made to feel that the author has himself gone over every step of the ground, but he follows the "Livret-Guide" too apparently in his geology. "Zürich and Glarus "- the title of Chapter xx.- gives an account of the variation in the movement of the old glacier which once filled the Lake of Zürich. The Glarus Mountains are described in accordance with Heim's well-known works. Chapter xxiv. on the Engadine is short. It explains the shifting northward of the watershed of the Alps, and the consequent formation of the line of lakes. The rocks of the Bernina, Julier; and Baselgia, are also indicated.

There are $\mathrm{I} 54$ illustrations in the book. Almost all are of the nature of geological sections or diagrams, 123 being reproductions from the works, mostly of Swiss geologists, and a few from English authors. The remainder are simple diagrams--with the exception of familiar photographs of the Rhone glacier, the Grimsel, and the valley of Chamonix ; a successful photograph of the rock-fold at the "Cascade of Arpenaz," and another of a "Scratched Pebble" from the moraine at Zürich. Two figures specially deserve to be noted, Figs. 49 and 50 , the front and side view of a river cone, as they, along with one or two drawings from Heim ("Bay of Uri," Fig. I4I, and "Volcanic Group of the Hohgau," Fig. I38), and from Baltzer ("View near the Grimsel," Fig. 37, and "View of the Jungfrau," Fig. I24), are the only illustrations which present to the eye of the reader scenic effects in combination with geological or physical truths. Like the text of the book, the illustrations are too technical for a thoroughly popular book on "Scenery." On the other hand, if the book lacks in imagination and style, it is not wanting in valuable and trustworthy facts, and these may be enough for the utilitarian mind.

A standard work amongst us already shows what can be made of the "Scenery" of a country in the hands of a geologist who is gifted with an artist's feeling for nature, and is a master of style. I refer to Sir Archibald Geikie's "Scenery of Scotland." Without this, we might have demanded less from Sir John Lubbock in his "Scenery of Switzerland." As it is, he has conferred a boon on the travelling English public, and broken new ground in the literature of the Swiss Alps.

NO. I 4O2, VOL. 54]

\section{THE TOTAL ECLIPSE OF THE SUN.1}

\section{III.}

TrondHJem, August I4

SINCE writing my last notes, the eclipse has come and gone, and we are homeward bound, rather depressed but satisfied that the Volages and ourselves had done our duty, and that it was Dame Nature alone who was to blame.

Although on the 8 th the weather in the forenoon was very fine and promising, towards the latter part of the day a change set in, and dark clouds came up.

Captain King Hall, who came over from the ship in the afternoon, soon detected what was wrong; there were two currents, an easterly and a westerly one, contending for mastery. This elemental war was watched with anxiety for two or three hours, and at times the weather chances improved, but later rain set in, and we could only hope against hope. It rained during our dinner-hour in the tent, an excellent one lent us by the War Department, kept dry under foot by a tarpaulin, and a deep trench outside cut in the peat. Lieut. Martin, the navigating officer, to whose constant care many of the admirable arrangements on the island were due, who had not only taken charge of the integrator, but who has ipsissma manu put up all three of the discs, ${ }^{2}$ remained on shore and did the honours.

A dim memory of the Latin grammar suggested champagne as an accompaniment of the well-cooked provender, for were we not bound on the morrow to face not only the ingens aquor, but, if all went well, something still more awe-inspiring.

Dinner over, the process of filling up all dark slides with the plates for the morrow was accomplished by Lieut. Martin, Mr. Fowler, and Dr. Lockyer, after which it was suggested that we should turn in early.

The Rev. E. J. Vaughan, my son, and I occupied one of the army tents, while Mr. Fowler and Lieut. Martin had their stretchers placed in Kiö Town Hall, as the 6 -inch hut had been called. Our last survey of the weather was not one to raise our spirits to any great extent, but we were still buoyed up by the observed fact that, as a rule, the early mornings, looking eastward, were moderately clear.

As we expected the Garonne, on her return from Spitzbergen, to anchor near our island some time in the early morning, we had arranged with the guard to light a beacon fire directly she was sighted, to show them our whereabouts

At I.30 my son took it into his head to take a stroll around outside; his attention was first drawn to the beacon burning brightly on the hill, and the four marines in their lammy suits standing by the side of it. Looming up very black and large, close to our island, was the good ship Garonne, before her time. It was not long before we received two nocturnal visitors, Captain Harry and Mr. Müller, who had come off to see about the day's arrangements. The weather was anything but pleasant, and their return to the ship was heralded by a downfall of heavy rain.

At 4 a.m. the parties, led by Captain King Hall, began to arrive from the ship, the first thing they did on landing being to make cocoa and breakfast. Mr. Thomas, in charge of the chronometer, and the readers of the thermometers, were the first to take their stations, and for these at the time of first contact the work began with the sky almost entirely covered with clouds, with narrow 1 Continued from page $42 \mathrm{r}$.

2 It may be worth while to state that the eye-pointers used in connection with the discs were impromptu affairs made by the ship's carpenter, but they promised to work well. There must be fine adjustments, because it is no likely that the point to be occupied by the eye will be calculated to an inch For these adjustments, then, we have first a horizontal bar, on which hangs a vertical piece of wood about ten inches long, free to slide. On this piece of wood slides up or down a piece of brass carrying a pointer marking the place of the eye; this is brought into position at the beginning of totality by the amanuensis. 
breaks near the sun's place, and wider ones near the horizon, a condition of things which relieved Mr. Fowler from his spectroscopic determination of the beginning of the eclipse.

Gradually everybody fell into their stations; the sketchers was clear that the 9 -inch prismatic camera would in all probability not be employed. Still Dr. W. Lockyer stood by at the mirror to make final adjustments.

A few minutes before totality, the delicate crescent was seen dimly through one of the breaks. I watched it

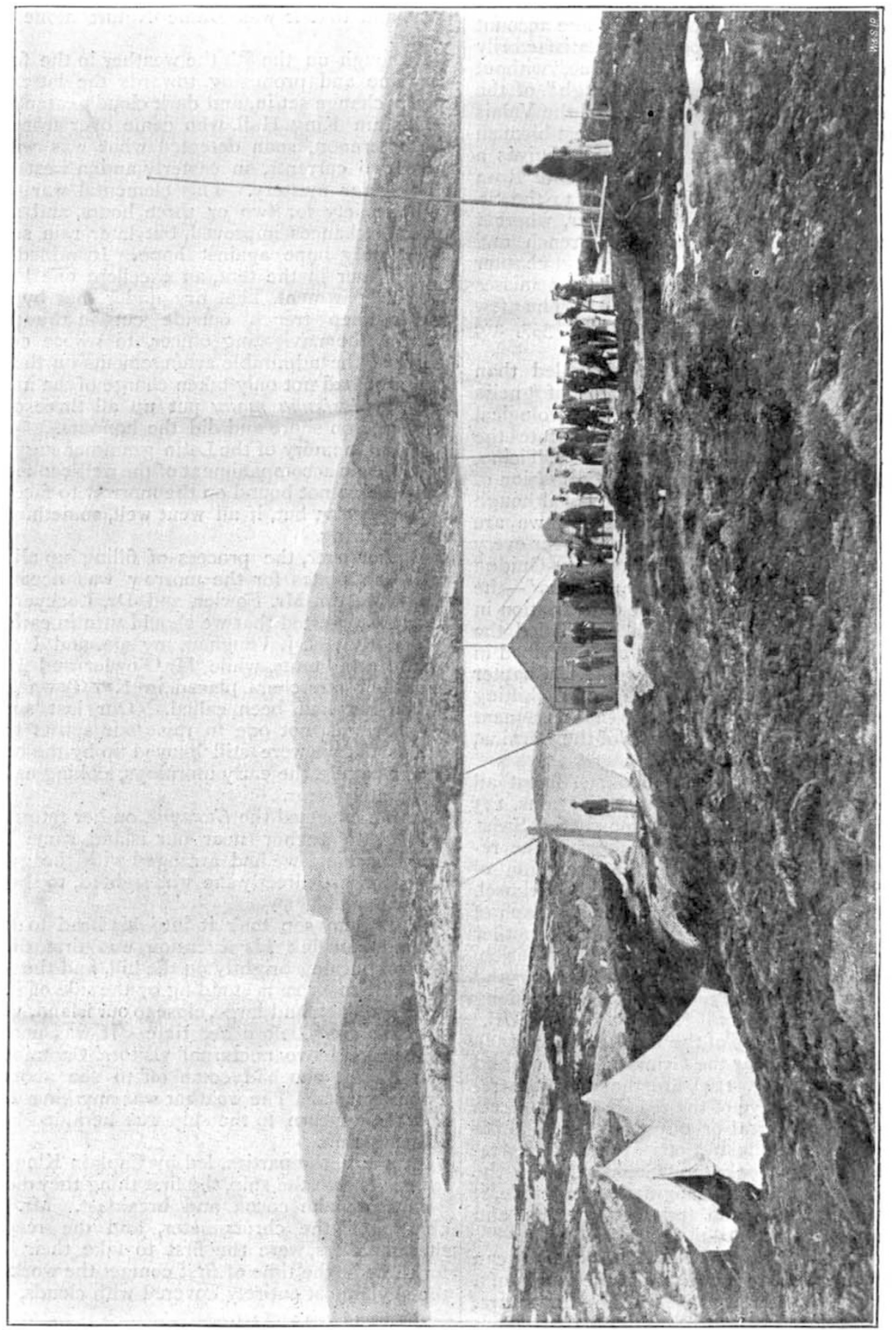

穿

went up the hill, but there was no need for them to carry out their instructions to shield their eyes by turning their backs to the sun.

There had been no sun to adjust the siderostat, so it in the $3 \frac{3}{4}$-inch for a minute or two, but the clouds closed up before the commencement. I gave it a little time, and then gave the signal, "Go," in order especially to start the 6-inch prismatic camera, as the important ten. NO. I 402 , VOL. 54] 
seconds-before-totality-signal could not be given in the way agreed upon. All the photographic work, with the exception of the 9-inch, then went on as if the eclipsed sun were visible. The actual commencement of totality
The time of the end of the eclipsed eclipse was also noted by Mr. Thomas, and the affair was over for most of us, although the colour observers and the meteorologists continued their notes till the fourth contact.

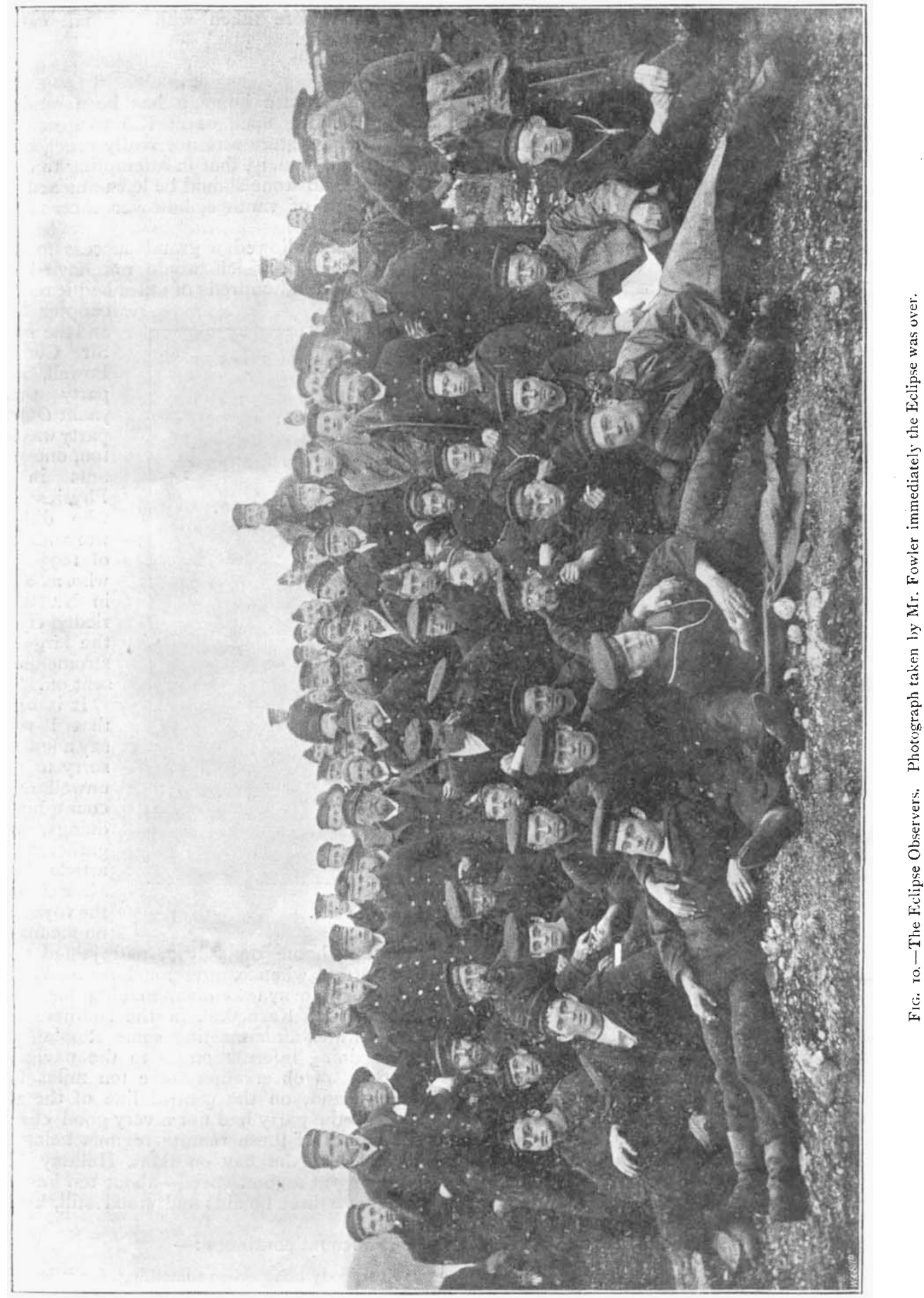

occurred shortly afterwards, the swoop of the shadow being almost felt. This instant was noted by $\mathrm{Mr}$. Thomas amid a cry for lamps, especially from the timekeepers and some of the observers in the huts.
And then an unexpected thing happened. Captain King Hall called his men together, and, in a few admirably chosen words, expressed to me the regret of the Volages that such an important attempt to advance knowledge NO. I 402 , VOL. 54$]$ 
had been frustrated. In reply, I told him that I thought an almost more important thing than the observation of a single eclipse had been accomplished. He had demonstrated that with the minimum of help, and that chiefly in the matter of instruments, such a skilled and enthusiastic ship's company as his could be formed in a week into one of the most tremendous engines of astronomical research that the world has ever seen; so that if the elements had been kind, all previous records of work at one station would have been beaten.

I added that I felt sure that the leaders of British science would thank him, his officers and men, for what they had done in aid of science when it came to be known, and further, that the kindness which the eclipse party had received on board the Volage had inspired a gratitude which it was not easy to express in words.

The party subsequently fell in to be photographed by Lord Graham and Mr. Fowler; then away to the ship for breakfast, and a curtailed Church service.

The repacking of the instruments was begun after break-
It was at Hammerfest that we first had news of any success, and that at Bodö. I had heard that there was a strong party of German astronomers at this place, but one of the fortunate ones, who subsequently came on board, told me, to my great regret, that there were no fixed instruments there at all, and that the photographs of the corona were taken with a small camera of the ordinary make.

Since my return home, it has been rendered evident that in inflicting upon us at Kiö so great a disappointment, Dame Nature was not really cruel, but was pointing a moral, namely, that in attempting to obtain records of eclipses, no stone should be left unturned in occupying every coign of vantage, however inconvenient or unpromising.

Hence she allowed a grand success to be scored at Novaya Zemlya, which would not have had a British observer within hundreds of miles had it not been for the chapter of accidents and the public spirit of Sir George BadenPowell, who took a party there in his yacht Otaria. In this party was Mr.Shackleton, one of the assistants in the Solar Physics Observatory, who did such good work during the eclipse of 1893 in Brazil, and who, as already stated in NATURE, was hurriedly equipped after the larger eclipse instruments had been sent off.

It is on his results that I wish here to say a few words. I am sorry to say he is too unwell to give an account himself of his doings, but I have gathered from an article in the Yorkshire Daily Post that the voyage itself was by no means uneventful. fast, as the Volage was to rejoin the squadron the next day. Under these circumstances the Town Hall was left standing for the benefit of the friendly Lapps whose island we had invaded, but who seemed rather to enjoy our doings than otherwise. Talking of the Lapps, it would be interesting to know the Lapp mythology and folk-lore concerning eclipses. Immediately after totality, or rather so soon as it was light enough to render the channel separating Kiö from the island to the eastward clearly visible, we saw a large boat full of Lapps firing a feu de joie. The fact may be chronicled. I was all the more struck by it, as it seemed to be possibly connected with the Eastern custom to light fires to frighten away Rahoo, whose swallowing of the sun causes the eclipse.

It seemed quite certain that the parties at Vadsö had fared no better than ourselves, and this was confirmed by the news brought by the Calypso's steam cutter in the afternoon. This cutter subsequently conveyed my son and myself to the Garonne, meeting her about a mile outside Kiö, and while the island was being rapidly left astern, full particulars were told me of all the camps which many of my shipmates had visited after the eclipse.

$$
\text { NO. I } 402 \text {, VOL. 54] }
$$

He left home on July 7 , and joined the Otaria at Hammerfest, whence, after touching at Vardö, the party sailed for Novaya Zemlya, making for the Samoyede settlement of Karmakul, in the southern island. The intention was, after meeting some Russian astronomers, and obtaining information as to the navigation, to take up a point of observation some ten miles further south, in Gooseland, on the central line of the shadow-path. Although the party had not a very good chart-m no trustworthy ones of these remote regions being publishedthey got into the bay on Bank Holiday Monday, and were going at a good speed-about ten knots-when the vessel gave three bounds and stood still, heeling over on her side.

The account continues :-

"Everybody hung on to something, for it was impossible to stand. Fortunately, however, the reef was only of soft rock, and it did little damage to the ship; only for four days we remained like that, about a mile away from the nearest land. We could not walk except by holding on to ropes, and had to get our meals on our knees or on the floor with cushions. After four days' hard work the sailors nearly emptied her, and pumped out all the drinking-water, and then at a high tide pulled her off." 


\section{It appears that}

"The mishap arose from a little want of familiarity with the Russian cartography of these parts, which is naturally better than ours. It turned out that the soundings of the deeper porfons were, so to say, in fathoms and the shallower in feet. A few of the deeper soundings having been verified by the lead, the rest were taken for granted, with the unpleasant result a'ready detailed."

Still, in spite of this mishap, everybody working with a will, things were more or less ship-shape on the eclipse morning. There had not been many opportunities of adjustment, but, not unmindful of possibilities, I had taken the precaution of having every portion of the more impoitant instruments adjusted, and each adjustment plainly marked before I sent it off.

Mr. Shackleton obtained twenty-one photographs with the prismatic camera, thirteen during totality, and five of the corona. I have already enlarged and begun to discuss these photographs, and I have seen enough already to be able to say that in my opinion the results obtained are of the highest possible value. In fact, we may almost say that

the long - talked - of "flash" has at last been photographed. This brings a test to apply to contending theories, and there will be a good deal to be written about it later on.

It is not too much to say that "the winter of our discontent" at Kiö is turned into "glorious summer" by the sun of Novaya Zemlya!

I must not forget to add that the photographs of the corona, though they are of much lower value from the theoretical point of view, will be very useful in enabling the change in the appearances of the corona from eclipse to eclipse in relation to the sun-spot period, to be chronicled.

The Yorkshire Daily Post states that Dr. Stone, who also accompanied Sir George Baden-Powell, has obtained some photographs of spectra.

I must be permitted one other extract from $\mathrm{Mr}$. Shackleton's statement, as it indicates the success of Sir George Baden-Powell's cruise in another direction, and is interesting as an account by an eye-witness of a most interesting event.

"After the eclipse we were busy repacking and getting all on board again. Our intention had been to go to the northern island to see about the safety of some stores which had been left there for Dr. Nansen, but we found it prudent to make direct for Hammerfest. Some of the Russian astronomers were about to make the attempt to cross Novaya Zemlya by means of dogs and sledges. ..."

"At Hammerfest, on our return, we heard that Dr. Nansen had arrived outside, and as the steamship Thor came in and dropped anchor alongside, the intrepid explorer recognised Sir George, whom he knew well, and halloed, 'Hallo, Baden" Powell, is that you? I did'nt expect to see you here.' Our cutter was out, and at once Sir George was rowed off to the Thor. Dr. Nansen returned with him immediately, to the disappointment of the Norwegians, who were playing their

$$
\text { NO. I 4O2, VOL. 54] }
$$

National Anthem, and making other demonstrations in his honour. This was on Tuesday, the I8th. Mrs. Nansen arrived by express steamer, and the Doctor was very anxious to see her again. When she arrived there was an affecting scene. The reunion proved too much for the feelings of the faithful wife, who fainted away, and did not recover consciousness for a considerable time. Then came redoubled rejoicings. The people of Hammerfest were too much delighted to leave their countryman much opportunity of private happiness, and made a feast in the public hall. Dr. Nansen was very anxious about the Fram, though he felt quite confident that she would be coming in. 'It is only,' said he, 'a question of a week or two,' but at the same time he appeared disappointed that she had not preceded him. Our yacht took Nansen on to Tromsö, but I left her at Hammerfest to return by express steamer. The Fram, as you will have seen from the papers, turned in near Tromsö. When our steamer reached Tromsö the people there were very much disappointed that we had not brought Nansen back with us. At Bodö we learnt of the receipt of a telegram announcing that the Fram had returned, but at first were inclined to treat the news as a joke. It, however, turned out to be correct; so for the second time we hoisted all our flags and bunting in honour of the Arctic exploring party." 